\title{
A educação trágica
}

\section{Resumo}

Apresentam-se primeiro os antecedentes da tragédia, as suas relações com o Estado ateniense e sua importância no calendário das festas oficiais e na vida política ateniense. Com as tragédias de Ésquilo Os Persas e Agamêmnon, exemplificam-se a estrutura e o conteúdo doutrinário da tragédia. Por fim, descreve-se o modo trágico de propor reflexão e de reatualizar os valores tradicionais.

Palavras-chave: Páthei Máthos; Hýbris; Áte.

\begin{abstract}
First, the antecedents of tragedy, its relationship with Athenian State and its significance in official festivals calendar and in political Athenian way of life are presented. By analysingAischylus' tragedies The Persians and Agamemnon, the structure and the teaching issues of tragedy are shown. Finally, the tragic way of stimulating reflexion and re-enacting the traditional values are described.
\end{abstract}

Keywords: Páthei Máthos; Hýbris; Áte.

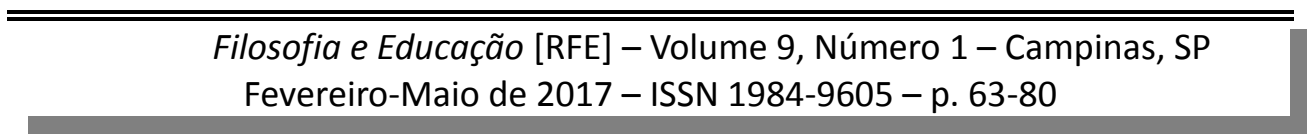




\section{Antecedentes}

tragédia surge no final do séc. VI em uma Atenas ainda obscura
e atrasada, e o desenvolvimento e esplendor da tragédia coincide
com o desenvolvimento e esplendor de Atenas. O comediógrafo Aristófanes e o filósofo Platão, êmulos e rivais da tragédia, atribuíam à tragédia tão influente poder na formação dos cidadãos, que não erraríamos se reconhecêssemos em parte à tragédia a influência inspiradora e configuradora da grandeza intelectual, política e militar de Atenas.

$\mathrm{Na}$ primeira metade do século VI, introduziram-se nas Panateneias recitais em que os bardos e rapsodos itinerantes de toda a Grécia concorriam com a obrigação de recitar os poemas homéricos Ilíada e Odisseia em ordem sequencial. Assim se preservou a produção épica já em declínio, e proveu-se a instrução de toda a população da Ática nos mitos heroicos panhelênicos, o que, aliado ao generalizado gosto pelo canto e pela dança corais, foi decisivo na invenção ateniense da tragédia (Else, 1967, p. 47).

Por volta de 534 a.C., instituíram-se as Grandes Dionísias, ou Dionísias Urbanas, abertas a todo o povo ateniense: tinham início com a procissão que trazia a estátua cultual do Dioniso Eleutereu, do santuário em Elêuteras, na fronteira entre Ática e Beócia, para o altar no teatro, acompanhada de sacrifícios e cantos; o espetáculo da tragédia era o centro do festival, e acrescentaram-se depois os concursos de ditirambo, o drama satírico e a comédia (Else 1967, 49).

\section{Tragédia e Estado}

Para compreendermos o alcance e a eficácia da tragédia como forma de educação estatal, examinemos primeiro as circunstâncias de sua 
representação e a natureza de seus vínculos com o Estado ateniense, e a seguir sua estrutura formal e conteúdo doutrinário.

No século V, a cultura de Atenas era destacadamente rica em festivais e competições musicais. Nesse calendário heortológico, a festa principal e mais suntuosa eram as Grandes Dionísias, realizadas no início da primavera (entre março e abril) em honra ao Deus Dioniso, a quem se consagravam também as Leneias no inverno (janeiro-fevereiro) e as Dionísias Rurais, celebradas nos campos em diferentes demos (distritos), em diferentes dias do inverno, antes das Leneias (Cartledge, 1997, p. 8).

Inicialmente os concursos trágicos se davam nas Grandes Dionísias e os cômicos nas Dionísias Rurais, depois tragédias se incluíram nestas, e comédias naquelas. O poeta trágico devia pedir o coro ao arconte epônimo (assim chamado por dar o seu nome ao ano civil), e o cômico ao arconte rei, que administrava o calendário de festas oficiais. $\mathrm{O}$ financiamento de todas as despesas da representação se fazia mediante o sistema de liturgias, em que o poder público indicava cidadãos abastados para arcar com os custos de determinados itens da política pública, fossem de trirremes (navios de guerra) ou de coros trágicos ou cômicos (Cartledge, 1997, p. 10).

Nas Grandes Dionísias, o concurso trágico ocupava três dias, a cada dia um poeta apresenta três tragédias e um drama satírico. Dez juízes, representantes de cada tribo, escolhiam o vencedor, com a determinação do primeiro, do segundo e do terceiro lugares, sendo aleatoriamente destruídos cinco de seus votos antes de serem conhecidos, para evitar suborno. Portanto, a grande vitória de fato para o poeta era obter o coro e poder mostrar sua arte a seus concidadãos.

Na primavera, o mar Egeu era navegável, e os delegados das cidades aliadas a (de fato, dominadas por) Atenas compareciam às Grandes Dionísias. Dois fatos políticos notáveis precediam o espetáculo das

Filosofia e Educação [RFE] - Volume 9, Número 1 - Campinas, SP
Fevereiro-Maio de 2017 - ISSN 1984-9605 - p. 63-80


tragédias: os tributos, impostos aos aliados, eram depositados à vista de todos na orquestra do Teatro de Dioniso; e os órfãos de guerra, educados pelo Estado ateniense, ao chegar à maioridade, eram apresentados à cidade, recebiam as armas de hoplita completas, e os nomes de seus pais mortos eram proclamados, com os votos de que lhes seguissem o exemplo na defesa da cidade (Goldhill, 1992, p. 101-105).

Dada a importância do teatro para a democracia ateniense, instituiu-se o "teórico" (theorikón), subsídio para cidadãos pobres pagar a entrada do teatro (Croally, 2008, 63).

\section{Tragédia e História}

Das centenas, talvez milhares, de tragédias compostas na época clássica, resta-nos hoje um espólio reduzido a trinta e duas peças integrais, a saber, sete de Ésquilo, sete de Sófocles e dezoito de Eurípides.

A mais antiga desse espólio, e a única com temática histórica, é $O s$ Persas (472 a. C), representada oito anos após o acontecimento nela descrito, a saber, a surpreendente derrota dos persas na batalha naval de Salamina, após terem invadido a Grécia e capturado Atenas. Por ter sido a estratégia vitoriosa concebida e promovida pelo comandante ateniense Temístocles, o crédito da vitória sobre a esquadra do rei Xerxes foi reconhecido a Atenas pelos espartanos, que, dez anos antes, em 490 a.C., conclamados, tinham chegado tarde para a batalha de Salamina, mas ainda em tempo para admirar a esplêndida vitória dos atenienses sobre o exército invasor de Dario, pai de Xerxes. Essas duas vitórias, com o intervalo de dez anos, prepararam os atenienses para assumir a hegemonia, que os espartanos lhes delegaram, na Liga de Delos, coligação das cidades gregas do mar Egeu com vista a expulsar os invasores persas remanescentes e prevenir novas invasões. Assumindo de bom grado a hegemonia da Liga, os atenienses logo 
a transformaram em império, criando assim para si um caminho político inteiramente novo na Grécia: a democracia na política interna, e o império na política externa.

Mas retornemos a Os Persas: o tema histórico e as personagens históricas - o rei Xerxes, a rainha mãe e o rei Dario, invocado como fantasma e evocado como paradigma de bom governante e de bons tempos pretéritos - não alteram a estrutura formal nem o conteúdo doutrinário da tragédia, uma vez que os mitos e figuras mitológicas constituíam para os gregos a sua representação do passado. Esta tragédia - e as outras, que a seguiram - constituem uma reflexão sobre os limites inerentes ao exercício do poder, os limites próprios da condição humana e o caráter inelutável da justiça divina. Esta reflexão se elabora com os elementos sensoriais e a dinâmica própria do imaginário mítico, dentro das categorias do pensamento mítico, antes (e em vez) da constituição conceitual da filosofia e da teoria política e ética.

A tragédia - toda tragédia - tem uma estrutura dúplice, em que se contrapõem o primeiro ator (protagonista) e o coro, tanto quanto - em outro sentido - se contrapõem o primeiro e o segundo atores (protagonista e antagonista). $\mathrm{O}$ ator recita, o coro canta e dança; eventualmente, em momentos intensamente patéticos, ator e coro cantam alternadamente (o que Aristóteles nomeia kommós, na Poética). Em geral, por um lado, o ator, com o uso da máscara que amplifica a voz e a figura, representa personagens míticas das epopeias homéricas e, por isso mesmo, do culto popular; por outro lado, constituído sempre por cidadãos, o coro, sem uso de máscara, mas com indumentária apropriada à sua personalidade coletiva, representa alguma coletividade e, além disso, por metonímia, representa também o ponto de vista da comunidade ateniense. Por sua personalidade coletiva e

\begin{tabular}{l}
\hline \hline Filosofia e Educação [RFE] - Volume 9, Número 1-Campinas, SP \\
Fevereiro-Maio de 2017 - ISSN 1984-9605 - p. 63-80
\end{tabular}


pela relação de permutabilidade entre os seus integrantes, o coro constitui uma metonímia da isonomia e igualdade democráticas.

Na Poética, Aristóteles assim nomeia as partes da tragédia: "prólogo", tudo que precede a entrada do coro, "párodo", o canto de entrada do coro na orquestra, "episódios", as partes faladas por atores entre os cantos corais, "estásimos", os cantos corais seguintes ao párodo, e "êxodo", tudo que segue ao último estásimo.

Nesse sentido, Os Persas não tem prólogo, e no párodo o coro se apresenta como "fiéis" guardiães do palácio, escolhidos pelo rei Xerxes, ao partir contra a Grécia com extraordinário exército. No primeiro verso, entretanto, há ambiguidade e mau presságio: tàde mèn Persôn tôn oikhoménon, "estes, dos persas que se foram", pois oikhoménon, que se refere ao rei e a seu exército, significa tanto "os que partiram" quanto "os finados". No v. 10, este mau presságio da palavra involuntariamente ambígua se explicita como "um maligno pressago ímpeto" que assalta o coro ao pensar no regresso do rei, e reitera-se o mau presságio: "pois toda a força / nascida da Ásia se foi” (vv. 11-12). Com esses presságios, o pranto saudoso de pais e esposas prenuncia o pranto lutuoso (vv. 13, 60-64).

A evocação dos chefes persas e do opulento exército incombatível e irresistível, que avança por terra e por mar, e a descrição de seu condutor como "hábil arqueiro Ares" (v. 85) não repelem o mau presságio nem tranquilizam o coro, antes trazem consigo duas noções premonitórias, "o fraudulento logro de Deus" (dolómetin d'apátan Theoû, v. 93) e "Erronia" (Áta. 98), que advertem os mortais dos incontornáveis perigos da grande riqueza e do poder excessivo.

No primeiro episódio, a entrada suntuosa da rainha mãe contrasta com sua aflição suscitada por sonho aziago, seguido de auspício igualmente aziago, que evidentemente confirma o sonho. O corifeu (corista líder) 
prudentemente a aconselha a fazer libações e preces à Deusa Terra, aos mortos e ao finado rei Dario, que aparecera no sonho. Antes de pôr os conselhos em prática, a rainha pergunta sobre Atenas, e a resposta do corifeu antecipa o elogio de Heródoto a Atenas como libertadora da Grécia (Hdt. VII, 139) e a oposição, cara a Heródoto, entre bárbaros-servos e gregoslivres, e rememora a vitória ateniense em Maratona. Entra, então, o mensageiro que anuncia a derrota do exército persa, com o que se confirmam os maus presságios e o sonho e o auspício aziagos.

O relato da batalha naval de Salamina pelo mensageiro coincide com o de Heródoto (Hdt. VIII), nos fatos narrados e na interpretação piedosa do surpreendente final como obra dos Numes (cf. vv. 345-348 e Hdt. VIII, 109, 3). A principal diferença é que o relato do historiador contém, além dos topônimos gregos e dos antropônimos persas, os nomes dos gregos que se notabilizaram na batalha, enquanto o relato trágico contém somente nomes dos chefes persas, mas de nenhum grego, pois a tragédia é a celebração da democracia ateniense e não de seus cidadãos, quaisquer que fossem.

No primeiro estásimo, a destruição do exército persa é atribuída primeiro a Zeus, depois a Xerxes e ainda aos navios e braços jônios (nesta tragédia, "jônio" significa "grego", segundo o modo persa de nomear os gregos). Esta concomitância de diversas causas é própria do pensamento mítico, e reatualizada na tragédia.

No terceiro episódio, a invocação e a aparição do espectro do rei Dario correspondem ao culto funerário dito "honras heroicas" (heroikai timai), que aqui revela aspectos oraculares e necromânticos. O espectro de Dario expõe uma interpretação dos fatos (vv. 808-813) já exposta pelo mensageiro (vv. 345-348) e inteiramente concordante com a interpretação que, segundo Heródoto, Temístocles fez dos mesmos acontecimentos (Hdt. VIII, 109, 3):

\begin{tabular}{l}
\hline Filosofia e Educação [RFE] - Volume 9, Número 1- Campinas, SP \\
Fevereiro-Maio de 2017 - ISSN 1984-9605 - p. 63-80
\end{tabular}


Paga de soberbia e de planos sem Deus

Ao chegar à Grécia, não temiam pilhar imagens de Deuses, nem queimar templos, e desaparecem altares e estátuas de Numes, arrancadas a esmo, reviradas dos pedestais. (Ésquilo, Os Persas, vv. 808-813)

Não somos nós os autores desta vitória, mas os Deuses e heróis, que recusaram que um único homem reinasse sobre Ásia e Europa, por ser ímpio e soberbo, que tratou do mesmo modo templos e casas, queimando e revirando estátuas de Deuses, que açoitou e encadeou o mar (palavras de Temístocles aos seus comandados em Hdt. VIII, 109, $3)$.

O espectro de Dario ainda revela antigos oráculos referentes ao porvir (vv. 814-820, fatos narrados também nas Histórias de Heródoto, a saber: a morte de Mardônio e o massacre dos persas em Plateia, Hdt. IX, 63-63, 70 e 83), e conclui: “A soberbia, ao florescer, produz a espiga / da erronia, cuja safra toda será de lágrimas." (Ésquilo, Os Persas, vv. 821-822).

Nas tragédias, as duas noções recorrentes, "soberbia" (hýbris) e "erronia" (áte), em geral são vistas em relação de reciprocidade como causa e efeito, ainda que nos versos acima a soberbia pareça preceder a erronia. A magnificência mesma do exército e da expedição militar contra a Grécia, a ponte lançada sobre o Helesponto (vv. 65-72, 721-725, 743-752) e a destruição de templos (vv. 808-813) configuram indistintamente tanto a soberbia quanto a erronia de Xerxes. No entanto, cada uma dessas palavras tem um significado distinto: hýbris, "soberbia", cognato do advérbio hypér, "acima", "mais ainda", também se traduz por "transgressão", "insolência", 
"desmedida"; áte, "erronia", cognato do verbo aáo, "extraviar", significa: 1) a punição divina, manifesta como cegueira moral, 2) atos em que essa cegueira se manifesta, e 3) ruína consequente desses atos (Chantraine, 1999, p. 3; Malta, 2006, p. 11).

Áte, "erronia", é uma figura divina e configura a justiça divina. Ao concluir sua avaliação dos atos temerários de Xerxes, o espectro de Dario diz: "Zeus punitivo vigia os demasiado / soberbos pensamentos, severo juiz" (Ésquilo, Os Persas, vv. 827-828).

A surpreendente e esmagadora derrota de Xerxes na Grécia, no entanto prenunciada por pressentimentos do coro e por sonho e auspício manifestos à rainha mãe de Xerxes, mostra como o Nume intervém no curso dos acontecimentos, e assim opera a justiça divina. A mesma dinâmica se verifica nas outras tragédias supérstites de Ésquilo: um temor inicial inquietante e obsessivo se intensifica até que se consume na revelação dos fatos em que se manifesta a justiça divina.

\section{Páthei Máthos: "saber por sofrer"}

A única trilogia de tema encadeado que nos chegou completa é a Oresteia (458 a.C.), composta de Agamêmnon, Coéforas e Eumênides. Sabemos que Os Sete contra Tebas (467 a. C.) é a terceira peça e As Suplicantes (463 a.C.) a primeira de suas respectivas trilogias, encadeadas, mas de Prometeu não temos informações seguras a esse respeito.

Em Agamêmnon, diz no prólogo o vigia que no teto do palácio dos Atridas em Argos observa o céu na expectativa do sinal de fogo anunciador da tomada de Troia. Manifesto o sinal, o vigia se livra dessa tarefa de cão, reiterando inquietante insinuação de que algo terrível ora se oculta no palácio.

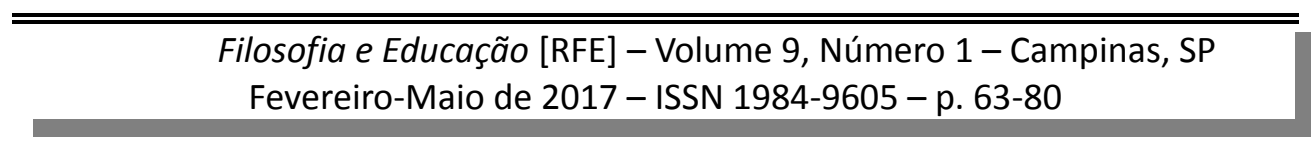


No párodo, o coro de anciãos argivos - perplexo entre a angústia pelo rei Agamêmnon ausente em prolongada guerra e a esperança suscitada por todos os altares de súbito repletos de oferendas em ação de graça - se pergunta, como se à rainha Clitemnestra, que notícia motivou tais oferendas. Para responder à sua própria questão, o coro rememora o auspício manifesto ao partir a expedição contra Troia (à direita duas águias devoram uma lebre prenhe e toda a cria) e sua ambígua interpretação pelo adivinho do exército.

Dada a ambiguidade do auspício e de sua interpretação oficial, o coro em busca de conforto invoca Zeus, fundamento da serenidade, do poder vitorioso e da sabedoria, de quem espera paz de espírito e prudência. Mas esse dom de Zeus impõe condições:

Ele encaminhou mortais

à prudência, ele que pôs

em vigor "saber por sofrer".

A dor que se lembra da chaga

sangra insone ante o coração

e a contragosto vem a prudência.

Violenta é a graça dos Numes

sentados em venerável trono.

(Ésquilo, Agamêmnon, vv. 184-191)

A fórmula páthei máthos, "saber por sofrer", recorrente com variações na Oresteia, pressupõe as noções míticas de verdade e de justiça como aspectos fundamentais do mundo. Páthos, no dativo páthei, se diz de toda experiência de que o sujeito é paciente. Inelutável e incontornável, Justiça (Dike), filha de Zeus, se manifesta no curso dos acontecimentos e, tal como a prudência, vem aos mortais a contragosto deles.

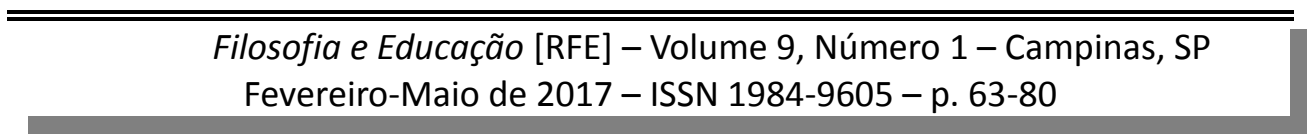


Daímon, "Nume", designa todo e qualquer Deus, celeste ou ínfero, sob o ponto de vista da relação desse Deus com o destino particular de um indivíduo, de uma casa ou de uma coletividade que esse Deus presida; Daímon, é por isso, uma das palavras gregas que às vezes se pode traduzir por "destino". O oximoro da asserção Daimónon dé pou kháris bíaios, “violenta é a graça dos Numes", marca o abismo intransponível da distância imensurável entre os mortais e a transcendência divina, a distância por onde a graça numinosa alcança os mortais na forma da violência.

Assim se explica a situação do rei Agamêmnon no inverno em Áulida dez anos antes, quando as circunstâncias, mediante novo pronunciamento do adivinho, definem claramente o ambíguo sentido do auspício das águias que devoravam a lebre prenhe e sua cria. A graça que se espera de Ártemis, a navegação para Troia, se dá por um "sacrifício outro insólito impartilhável" (v. 150), em que em vez de cabra (cf. v. 232) a vítima seria sua filha Ifigênia. O rei se vê coagido a ou desertar do pacto ou sacrificar a filha (vv. 206-208)

A coerção faz o rei ver a liceidade deste sacrifício:

O sacrifício de cessar-vento

e o virgíneo sangue, desejá-los

com superfurioso furor,

é lícito, pois que bem seja!

(Ésquilo, Agamêmnon, vv. 214-217)

Sabemos que, em tempos históricos, o exército espartano se deslocava conduzindo consigo um bando de cabras para se sacrificar a Ártemis nas fronteiras naturais, como o limite entre a cidade e o campo, cursos d'água, e na linha de frente da batalha. Ártemis preside a fronteira entre civilização e

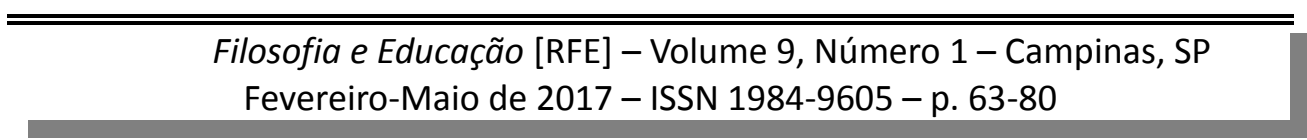


selvageria, e com o sacrifício da cabra se pede à Deusa anuência à transposição de sua fronteira. Parece ser esse o sentido do sacrifício em Áulida, última fronteira de terra grega antes da planície do mar - ao menos em Ésquilo, que, ao contrário de Sófocles em Electra e de Eurípides em Ifigênia em Áulida, não alega nem explicita nenhuma razão desse sacrifício.

No entanto, ao ponto de vista do herói, que pode ver liceidade e bem nesse sacrifício insólito, se contrapõe o ponto de vista do coro, que só pode ver nesse sacrifício desfaçatez e violação de todas as normas divinas e humanas:

\author{
Quando sob o jugo da coerção \\ respira ímpia mudança de ânimo \\ nem pura nem sacra, doravante \\ concebeu pensar toda ousadia: \\ mísera demência mestra de vilezas \\ faz audazes mortais, matriz de males. \\ Ousou fazer o sacrifício \\ da filha: auxílio aos combates \\ vingadores de mulher \\ e primícias por navios. \\ (Ésquilo, Agamêmnon, vv. 218-227)
}

Essa contraposição entre o herói e o coro contrapõe também os valores da antiga aristocracia, que a tragédia em geral tende a fundir e confundir com os da tirania mais recente, e os da presente democracia. No entanto, apesar da reprovação frontal dessa "ousadia" do rei, o coro de anciãos, por lealdade ao rei, detém-se e recusa-se a descrever a execução mesma do sacrifício, preservando, no entanto, a confiança tanta na arte divinatória do vate quanto no caráter inelutável da justiça divina:

Filosofia e Educação [RFE] - Volume 9, Número 1 - Campinas, SP
Fevereiro-Maio de 2017 - ISSN 1984-9605 - p. 63-80


O depois disso não vi nem digo.

Artes de Calcas não são sem efeito.

Justiça impõe que a saibam

os que a sofrem, e o porvir,

quando viesse, ouvirias. Antes, alegre-se!

(Ésquilo, Agamêmnon, vv. 248-252)

Silêncio reverente, mas respaldado na fórmula páthei máthos, "saber por sofrer", referida à justiça divina, que se faz reconhecer por aqueles a quem pune.

Comunicada pela rainha Clitemnestra a captura de Troia, e vencida a incredulidade inicial da surpresa, o coro, enfim convencido da veracidade dessa notícia, se dispõe a orar em agradecimento aos Deuses.

No primeiro estásimo, essa prece em agradecimento aos Deuses se desdobra numa análise do sentido dos acontecimentos, desde o rapto de Helena por Páris no palácio de Menelau até as consequências da guerra para ambos os lados envolvidos. Nessa análise, o coro constata que:

1) na destruição de Troia se manifesta a justiça de Zeus, pois as circunstâncias do rapto constituem ofensa a Zeus Hóspede (Xénios, v. 362), a justiça é coletiva e a punição se estende a todos;

2) no viço da grande riqueza de Troia, surge a audaz Persuasão (Peithó, v. 385), filha intolerável da conselheira Erronia (Áte, 386), que induz o príncipe à transgressão da justiça;

3) o rapto de Helena por Páris traz o luto junto ao lar de Menelau, mas a expedição dos reis Atridas Agamêmnon e Menelau contra Troia traz o luto junto aos lares gregos, pois "toda a dor tolerável / em casa brilha": “em vez

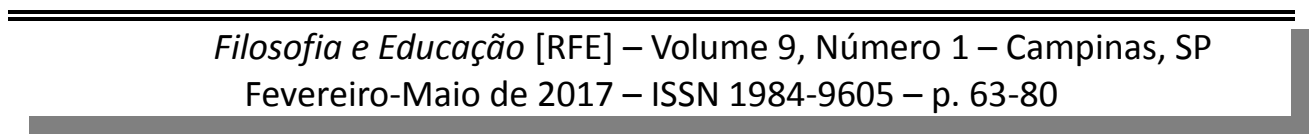


de homens / armas e cinzas chegam / à casa de cada um” (vv. 434-436), “outros lá perto da muralha / intactos têm tumba em Ílion” (vv. 453-454);

4) “Grave é a palavra de cidadãos irada / e cumpre o devido à imprecação pública" (vv. 456-457); "Deuses não são sem vigilância / dos matadores de multidão" (vv. 461-462); as negras Erínies, filhas da Noite imortal, são a face sombria da justiça penal de Zeus, e elas "a seu tempo / cegam afortunados sem justiça / no fortuito revés da vida" (vv. 463-465).

Diante dessa equivalência entre o resultado do delito de Páris (dor e luto no lar de Menelau) e da expedição justiceira dos Atridas (dor e luto nos lares gregos), e diante da constatação de que "grave é o grande alarde / de glória" (vv. 467-468), o coro tira duas conclusões diversas, uma referente a si mesmo, outra referente à notícia da queda de Troia anunciada pelo fogo mensageiro: primeiro louva a riqueza que não suscite a recusados Deuses (áphthonon ólbon, v. 471) e pede para si viver com liberdade e com moderação (vv. 472-474), e depois recua do assentimento dado à notícia trazida pelo fogo, porque a sua lealdade ao rei o impede de aceitar que pendem sobre o rei as previsíveis consequências que se inferem dessa anunciada vitória, tão mortífera e tão lutuosa.

No segundo episódio, o arauto faz o anúncio do retorno do rei vitorioso e os termos da proclamação de sua vitória confirmam as razões dos temores que fizeram o coro recusar-se a aceitar a notícia dada pela rainha:

Ele revolveu Troia com a enxada de Zeus portador de justiça, lavrado está o solo.

Altares desaparecidos e estátuas de Deuses e semente da terra toda está perecendo: lançou tal jugo ao redor de Troia [...] 
(Ésquilo, Agamêmnon, vv. 525-529)

Essas palavras do arauto contrariam as condições impostas aos vencedores para que não sejam por sua vez vencidos - condições declaradas pela rainha ao comunicar ao coro a notícia do fogo mensageiro (vv. 338342). Na exaltação da vitória o arauto proclama feitos que constituem sacrilégios e ofensa aos Deuses - destruição de altares e estátuas de Deuses -, o que o espectro de Dario (Ésquilo, Os Persas, vv. 809-812) e Temístocles (Hdt, VIII, 109,3) consideram causa da derrota infligida a Xerxes pelos Deuses em Salamina. A desproporção entre a afronta perpetrada por Páris e a punição imposta por Agamêmnon também constitui iniquidade e incorre na cólera divina, pois "Deuses não são sem vigilância / dos matadores de multidão" (vv. 461-462). Em vista disso, por sua lealdade ao rei, o coro considera "grande graça a morte agora" (v. 550), invertendo o sentido da fala do arauto (cf. v.539), pois o arauto pouco antes dissera não recusar aos Deuses morrer, porque o júbilo do não mais esperado retorno à pátria dava à vida a inexcedível plenitude da perfeição, enquanto o coro vê na morte "grande graça" porque, em sua lealdade ao rei, a vida se the esvazia de sentido ao prever para o rei o golpe da justiça divina.

O segundo estásimo reitera com novas imagens a análise da queda de Troia como consequência da grande riqueza que traz consigo a soberbia (hýbris) e a erronia (áte), em que, acometido de cegueira moral, o transgressor age contra os seus próprios interesses, de modo a destruir-se:

Soberbia antiga sói

parir soberbia nova

entre os males dos mortais

cedo ou tarde, ao vir

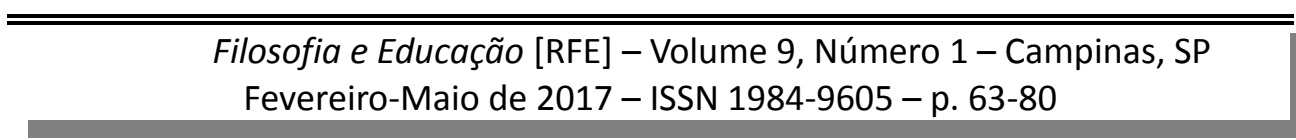


o dia próprio do parto:

O Nume indômito invicto,

a ímpia audácia

da negra fúria no palácio

parecida com seus pais.

(Ésquilo, Agamêmnon, vv. 763-771)

No terceiro episódio, esta doutrina do parto de nova soberbia pela antiga se aplica ao rei Agamêmnon na cena da recepção do rei pela rainha, quando esta lhe pede:

Desce desse carro, sem pôr no chão

o teu pé devastador de Ílion, ó rei.

Por que tardais, ó servas, incumbidas

de cobrir o chão da via com as vestes?

Rápido se cubra de púrpura o acesso

à casa inopina a que Justiça o guia.

(Ésquilo, Agamêmnon, vv. 906-911)

Neste pedido da rainha ressoa ominosa ambiguidade: "descer do carro sem pôr o pé no chão" implica a supressão de base firme, queda: "cobrir-se de púrpura o acesso" implica homicídio e sangue derramado no chão; "casa inopina" duplica o inesperado retorno ao lar em morte e inesperada descida à casa de Hades; e "Justiça" diz tanto "recompensa" quanto "reparação".

Inicialmente, Agamêmnon recusa essa honraria alegando a sua inadequação: o insigne elogio tem que vir de outros e não dos familiares; aclamações aos gritos e prostração são modos bárbaros, não gregos; Deuses assim se devem honrar, não mortais; o mortal não pode andar sem pavor (sem temor dos Deuses) sobre os enfeitados adornos. No entanto, em 
esticomitia (vv. 931-943), Clitemnestra refuta rápido todas as ressalvas do rei, e remata com ominosa duplicidade: "deixa-te persuadir, concede-me poder" (v. 943), onde "poder" não significa somente o poder de persuadir, mas sobretudo o poder de rei.

A entrada de Agamêmnon no palácio pisando púrpuras o mostra seduzido por soberba, cegado por erronia (v. 957). No terceiro estásimo, os anciãos do coro, leais ao rei, são tomados de vaticinante temor, descrito como assediante nênia de Erínis. No quarto episódio, a adivinha Cassandra, cativa que compartilha o destino fatídico do rei, tem a visão numinosa que revela crimes sangrentos passados e futuros do palácio real; o coro confirma os crimes passados e recusa-se a aceitar e entender os futuros, mas, após a profetisa entrar no palácio para morrer, os gritos do rei denunciam a ação de seus matadores. No último episódio, os regicidas reivindicam os homicídios como atos de justiça, no que são contestados e desafiados pelos anciãos, inconformados e impotentes.

\section{Novos velhos valores}

A tragédia não oferece modelos de conduta, mas mostra conflitos, contradições, erros de avaliação e obstinações fatídicas, que estimulam a reflexão e põem em questão os paradigmas tradicionais. Os heróis mitológicos, personagens da epopeia, são colocados no contexto e na perspectiva do Estado democrático de Atenas, numa sobreposição de épocas, de instituições e de práticas sociais, que por um lado ressaltam a inadequação de certas condutas aristocráticas - como a soberbia (hýbris), a ousadia (tólma) e a obstinação (authadía) - e, por outro lado, reatualizam outros valores tradicionais, comunicando-lhes um novo sentido e novas ressonâncias, eminentemente democráticas - como a moderação (sophrosýne) e a prudência (phrónesis). 


\section{Referências bibliográficas}

CARTLEDGE, Paul. 'Deep plays': theatre as process in Greek civic life. In: EASTERLING， P. E. (Ed) 1.ed. Greek Tragedy. Cambridge: Cambridge University Press, 1997, 392p.

CHANTRAINE, Pierre. Dictionnaire étymologique de la langue grecque. 2.ed. Paris: Klincksieck, 1999, 1452p.

CROALLY, Paul. Tragedy's Teaching. In: GREGORY, Justina (Ed.) Greek Tragedy. 1.ed. Oxford: Blackwell, 2008, 552p.

ELSE, Gerald F. The Origin and Early Form of Greek Tragedy. 1.ed. Harvard: Havard University Press,1967, 127p.

GOLDHILL, Simon. The Great Dionysia and Civic Ideology. In: WINLER, John J.; ZEITLIN, Froma I. Nothing to Do with Dionysos? 1.ed. Princeton: Princeton University Press,1992, 422p.

MALTA, André. A Selvagem Perdição. 1.ed. São Paulo: Odysseus, 2006, 422p. 